\title{
Q ualidade fisiológica de sementes de pitangueira submetidas a diferentes procedimentos de secagem e substratos - Parte 2
}

\author{
Lúcia H. de M. Sena ${ }^{1}$, Valderez P. Matos ${ }^{1}$, Anna G. de F. A. Sales ${ }^{2}$, Elane G. B. de S. Ferreira2 \& Mauro V. Pacheco ${ }^{3}$
}

\begin{abstract}
RESUMO
Conduziu-se este trabalho com o objetivo de determinar o procedimento de secagem e substratos ideais para avaliar a visibilidade e o vigor das sementes e crescimento inicial das plântulas de pitangueira (Eugenia uniflora L.). U tilizou-se o delineamento inteiramente casualizado, em esquema fatorial $2 \times 4$ ( 2 procedimentos de secagem: à sombra e ao sol; 4 substratos: Areia, vermiculita, pó-de-coco e papel toalha), com quatro repetições de 25 sementes cada uma e se avaliaram os seguintes parâmetros: tempo médio de germinação, comprimento da raiz e do epicótilo e massa seca da plântula. 0 experimento foi conduzido em germinador tipo BOD, regulado a temperatura constante de $25 \stackrel{\circ}{\circ} \mathrm{C}$ e regime de luz contúnua. 0 procedimento de secagem à sombra e o substrato vermiculita podem ser recomendados para testar o vigor dessa espécie.
\end{abstract}

Palavras-chave: Eugenia uniflora, semente recalcitrante, sombra, vigor

\section{Physiological quality of surinam cherry seeds submitted to different procedures of drying and substrates - Part 2}

\begin{abstract}
This study had as its objective the determination of ideal procedure of drying and the substrate to evaluate the vigour and the initial growth of surinam cherry seedlings (Eugenia uniflora L.). The used design was entirely randomized in factorial scheme $2 \times 4$ ( 2 procedures of drying: shade and sun; 4 substrates: sand, vermiculite, coconut fiber and paper towels) with four replications of 25 seeds each. The following parameters were also analyzed: average time of germination, length of primary root and epicotyl and dry weight of the seedling. The experiment was conducted in BOD regulated at constant temperature of $25 \stackrel{\circ}{ } \mathrm{C}$ and regime of continuous light. The shade method of drying and the vermiculite substrate can be recommended to test the vigour of this specie.
\end{abstract}

Key words: Eugenia uniflora, recalcitrant seed, shade, vigour

${ }^{1}$ DEPA/UFRPE, Rua Dom Manuel de Medeiros s.n., Dois Irmãos, CEP 52171-900, Recife, PE. Fone: (81) 3320-6250. E-mail (s): Iu_cia_@hotmail.com, vpmatos@ig.com.br

${ }^{2}$ DCFL/UFRPE. Fone: (81) 3320-6250. E-mail (s): seedsannaballet@yahoo.com.br; egbsf@bol.com.br

${ }^{3}$ DAP/UFRN, Av. Senador Salgado Filho, s/n, Campus Universitário, CEP 59092-970, Natal, RN. Fone: (84) 3225-3700. E-mail: pachecomv@ufrnet.br 


\section{INTRODUÇÃO}

A pitangueira, Eugenia uniflora L. (Myrtaceae), espécie nativa do Brasil, é valorizada pelo fruto rico em vitamina A e vitamina $C$, além de vitamina $B_{2}$, ferro (Sete Ervas, 2004), cálcio, fósforo, antocianinas, flavonóides e carotenóides (Silva, 2006). Sua madeira é utilizada para a formação de cercas vivas, mourões, esteios, para lenha, enquanto o cerne escuro do tronco dos espécimes mais velhos tem utilidade na marcenaria de luxo. Suas folhas contêm o alcalóide denominado pitanguina (sucedâneo de quinino), e seu chá é utilizado contra afecções do fígado, em gargarejos para combater infecções da garganta e contra gota (Sete Ervas, 2004).

Normalmente, após a colheita as sementes apresentam excesso de umidade e grande quantidade de impurezas e, na maioria das espécies nativas, se encontram aderidas aos frutos, o que inviabiliza seu uso imediato (Marcos Filho, 2005). Uma vez coletados, os frutos devem ser despolpados e as sementes postas para secar adequadamente, beneficiadas e armazenadas em condições ideais para que não percam o poder germinativo em curto espaço de tempo (Paiva \& Gonçalves, 2001).

Os trabalhos envolvendo procedimentos de secagem de espécies frutíferas ainda são escassos, podendo-se citar aquele desenvolvido por Becwar et al. (1983), ao verificar que a secagem de sementes de maracujá (Passiflora edulis Sims f. flavicarpa Deg) até teores de água entre 2 a $15 \%$, não causou morte das mesmas; por Gouveia et al. (2003), determinando curvas de secagem em frutos de cajá (Spondias lutea L.); por Kohama et al. (2006), ao constatarem que as sementes de grumixameira (Eugenia brasiliensis Lam) apresentaram prejuízos à qualidade fisiológica após a secagem, e por Silva et al. (2007) que utilizaram o procedimento de secagem à sombra para sementes de jaqueira (Artocarpus integrifolia L.).

As sementes de pitangueira se comportam como sementes recalcitrantes; portanto, não suportam, teores de água abaixo de níveis relativamente altos (40 a 50\%) sem perda de viabilidade (Roberts, 1973). Para as sementes recalcitrantes vários fatores podem contribuir para esta diferença, incluindo-se o teor de água no momento da dispersão, a velocidade de secagem e o grau de maturação (Delgado, 2006).

A germinação é a emergência e o desenvolvimento das estruturas essenciais do embrião, manifestando sua capacidade para originar uma plântula normal, sob condições favoráveis (Brasil, 1992). Alguns substratos podem ser utilizados para testes de germinação de sementes, como a areia, papel mata-borrão, papel-toalha, pó-de-coco, tropstrato ${ }^{\circledR}$ e vermiculita (Medeiros \& Zanon, 1998; Andrade et al., 2000; Varela et al., 2005; Pacheco et al., 2007)

A escolha adequada do substrato é fundamental para a germinação das sementes visto que, através dele, serão suprimidas as quantidades de água e oxigênio necessárias para o desenvolvimento da plântula; além disso, em condições de laboratório o substrato funciona como suporte físico para que as sementes se desenvolvam (Marcos Filho et al., 1987). A capacidade de retenção de água de cada substrato, aliada às características intrínsecas que regulam o fluxo de água para sementes, influencia sensivelmente a germinação (Andrade \& Pereira, 1994).

Em virtude da importância de pesquisas sobre germinação, inclusive relacionadas às espécies nativas objetivou-se, no presente trabalho, determinar o procedimento de secagem para obtenção de sementes de alta qualidade e os substratos ideais para a avaliação segura do vigor das sementes e crescimento inicial das plântulas de pitangueira.

\section{MATERIAL E MÉTODOS}

Os frutos da pitangueira (Eugenia uniflora L.), fisiologicamente desenvolvidos, foram coletados de árvores pertencentes a um pequeno produtor, localizado no município de Bonito, Pernambuco, PE, em setembro de 2006 e em seguida conduzidos ao Laboratório de Sementes do Departamento de Agronomia da Universidade Federal Rural de Pernambuco (UFRPE), a fim de serem despolpados manualmente; as sementes foram postas para secar sobre tecido de algodão, eliminando-se as sementes imaturas, deterioradas ou danificadas por insetos.

As sementes foram secadas à sombra e ao sol, por um período de $72 \mathrm{~h}$, sendo estas cobertas no final da tarde com a finalidade de facilitar a difusão da umidade interna para a parte externa da semente, bem como das sementes mais úmidas para as mais secas, o que resulta em secagem mais homogênea. A secagem à sombra foi efetuada deixando-se as sementes em local com sombra, durante $72 \mathrm{~h}$.

Em ambos os procedimentos as sementes foram postas para secar sobre tecido de algodão e, à medida em que se processou a secagem, as sementes foram constantemente revolvidas a fim de propiciar melhor aeração em toda a massa e secagem mais uniforme. Nesta ocasião, a temperatura média atingida durante as $72 \mathrm{~h}$ de secagem à sombra, foi de $27,5^{\circ} \mathrm{C}$ e, ao sol, $34^{\circ} \mathrm{C}$.

As sementes foram armazenadas em recipientes de vidro com tampas vedadas durante três meses, em ambiente de laboratório; após este período, determinou-se o teor de água apresentado pelas sementes, segundo Brasil (1992), utilizando-se duas repetições de 50 sementes cada uma. As sementes submetidas a secagem à sombra, apresentaram teor médio de água de $47 \%$ enquanto as submetidas a secagem ao sol indicaram $45 \%$.

Antes da instalação do experimento as sementes foram desinfestadas com uma solução de hipoclorito de sódio a 5\% durante 5 min. e, em seguida, lavadas com água deionizada.

A semeadura ocorreu entre os substratos areia, vermiculita fina, pó-de-coco e papel toalha. Os três primeiros substratos foram previamente autoclavados, permanecendo em aquecimento a $120^{\circ} \mathrm{C}$, por $2 \mathrm{~h}$; posteriormente foram postos para secar e colocados em caixas plásticas transparentes de $11 \mathrm{x}$ $11 \mathrm{x} 3 \mathrm{~cm}$, com tampa (gerbox) e, por fim, umedecidos com solução de Nistatina a $0,2 \%$, adotando-se $60 \%$ da capacidade de retenção do substrato. Com relação ao substrato papel toalha, este foi umedecido com a mesma solução de Nistatina a $0,2 \%$, na proporção de 3 vezes o peso do papel e organiza- 
do em forma de rolo, segundo prescrições de Vieira \& Carvalho (1994).

Conduziu-se o experimento em germinador do tipo Biochemical Oxigen Demand (BOD), regulado a temperatura constante de $25^{\circ} \mathrm{C}$ e regime de luz contínua, utilizando-se quatro lâmpadas fluorescentes de $20 \mathrm{~W}$, tipo luz do dia.

O número de sementes germinadas foi avaliado diariamente adotando-se, como critério de germinação, o surgimento do epicótilo que, segundo Oliveira (1993) é a porção do eixo ascendente da plântula compreendida entre o ponto de união dos cotilédones e o da primeira folha ou par de folhas.

Os parâmetros seguintes foram avaliados: tempo médio de germinação: realizado de acordo com a fórmula citada por Silva \& Nakagawa (1995), com os resultados expressos em dias após a semeadura; comprimento da raiz e do epicótilo: no final do teste de germinação e com o auxílio de uma régua graduada em centímetros, mediu-se o comprimento da raiz primária e do epicótilo das plântulas normais de cada repetição, cujos resultados foram expressos em centímetro por plântula; massa seca das plântulas: as plântulas normais de cada repetição empregadas na avaliação do comprimento, foram acondicionadas em sacos de papel, previamente identificados e levados à estufa de ventilação forçada, regulada a $80{ }^{\circ} \mathrm{C}$ durante $24 \mathrm{~h}$ e pesadas em balança analítica com precisão de $0,0001 \mathrm{~g}$, cujos resultados foram expressos em mg por plântula, segundo a metodologia descrita por Nakagawa (1999).

Realizou-se a análise de variância de acordo com o delineamento experimental inteiramente casualizado, tendo-se realizado as transformações dos dados de porcentagem em arcsen $(\mathrm{x} / 100)^{0,5}$, com os tratamentos distribuídos em arranjo fatorial 2 x 4 (dois procedimentos de secagem e quatro substratos), com quatro repetições de 25 sementes cada uma; na análise estatística usou-se o programa ESTAT Sistema de Análise Estatística (ESTAT, 1994) desenvolvido pela FCAV/ UNESP, Jaboticabal, SP, e as médias foram comparadas pelo teste de Tukey a $5 \%$ de probabilidade.

\section{RESULTADOS E DISCUSSÃO}

$\mathrm{Na}$ avaliação da qualidade fisiológica das sementes em função dos dois procedimentos de secagem e substratos, não se verificou efeito significativo da interação para o tempo médio de germinação (Figura 1).

Dentre os procedimentos de secagem (Figura 1), pode-se constatar que a secagem à sombra (40,63 dias) foi o procedimento que proporcionou menor tempo médio de germinação, diferenciando-se em 19 dias do procedimento de secagem ao sol (59,11 dias), ou seja, proporcionou um decréscimo de $31,27 \%$ no tempo que levaria para germinar.

Com relação aos substratos (Figura 1), a vermiculita (39,0 dias) promoveu menor tempo médio de germinação às sementes de pitangueira, diferentemente do observado para os substratos areia (56,37 dias), pó-de-coco (52,9 dias) e papel toalha (51,23 dias) que não diferiram entre si.

O tempo necessário para determinada amostra de sementes germinar depende, primariamente, da espécie em estudo e

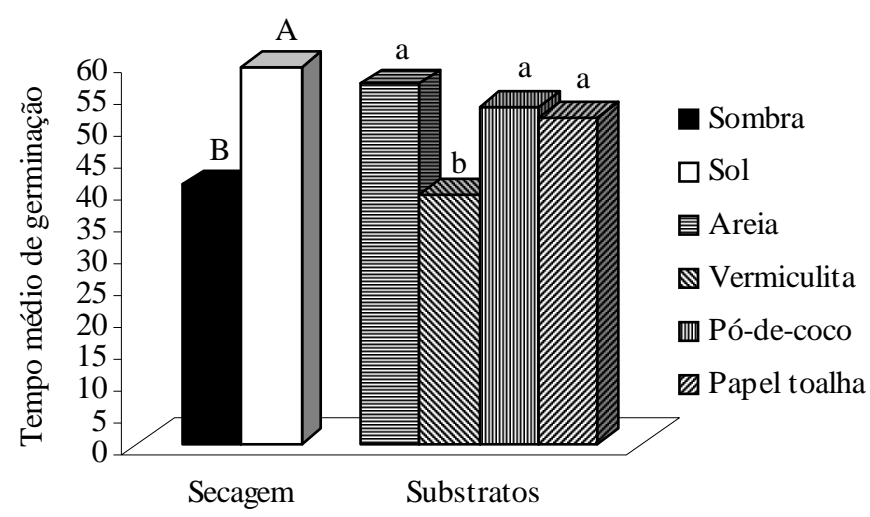

Médias seguidas da mesma letra maiúscula para os procedimentos de secagem e minúscula para os substratos, não diferem entre si pelo teste de Tukey a $5 \%$ de probabilidade. $\mathrm{CV}=10,74 \%$

Figura 1. Tempo médio da germinação (dias) de sementes de pitangueira (Eugenia uniflora L.) submetidas a diferentes procedimentos de secagem e substratos.

das condições experimentais ou ambientais nas quais elas se encontram (Ferreira \& Borghetti, 2004).

Os maiores valores de comprimento radicular $(16,07 \mathrm{~cm})$ foram observados em plântulas provenientes de sementes submetidas ao procedimento de secagem à sombra e semeadas no substrato papel toalha. O substrato papel toalha também demonstrou ser adequado ao crescimento radicular de plântulas $(11,57 \mathrm{~cm})$ oriundas de sementes secadas ao sol; no entanto, este apresentou redução de $28 \%$ em relação aos valores obtidos para o procedimento de secagem à sombra e não diferiu significativamente do substrato vermiculita $(9,51$ cm) (Figura 2).

\section{目 Areia $\mathbb{Q}$ Vermiculita $\mathbf{m}$ Pó-de-coco $\mathbf{Z}$ Rolo de Papel}

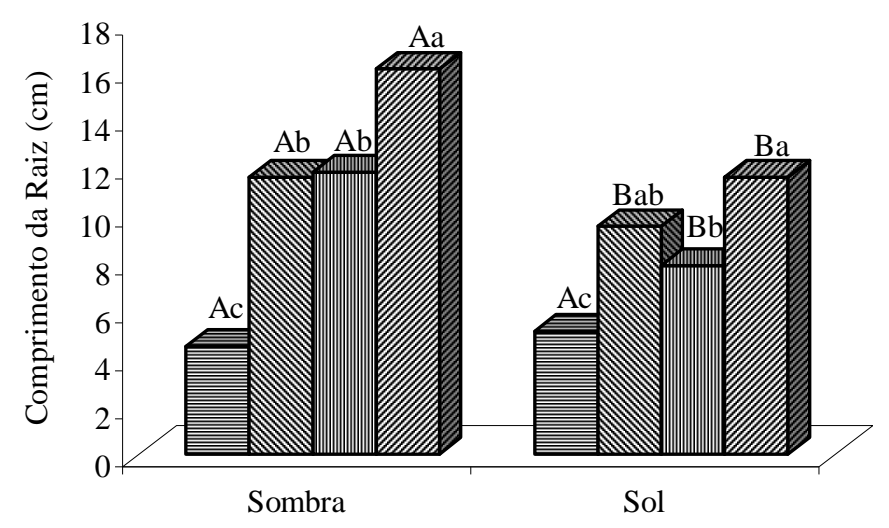

Médias seguidas da mesma letra maiúscula para os procedimentos de secagem e minúscula para os substratos, não diferem entre si pelo teste de Tukey a $5 \%$ de probabilidade. $\mathrm{CV}=13,81 \%$

Figura 2. Comprimento da raiz primária (cm por plântula) das plântulas de pitangueira (Eugenia uniflora L.) submetidas a diferentes procedimentos de secagem e substratos.

Constatou-se, na Figura 2, que as sementes de pitangueira postas para germinar no substrato areia originaram plântulas com menor comprimento radicular $(4,5$ e 5,14 cm) em ambos os procedimentos de secagem, ocorrendo um decréscimo de $72 \%$ em relação ao substrato papel toalha 
para as sementes secadas à sombra e de $56 \%$ quanto àquelas secadas ao sol.

Pacheco et al. (2008) constataram que o papel toalha foi o único substrato que proporcionou maior comprimento radicular em todas as temperaturas $\left(25,30,35,20-30,20-35^{\circ} \mathrm{C}\right)$ utilizadas no estudo da ecofisiologia da germinação de sementes de craibeira (Tabebuia aurea (Silva Manso) Benth. \& Hook. f. ex. S. Moore). Os autores afirmam que tais resultados obtidos podem ser atribuídos ao maior espaçamento entre as sementes, o que foi proporcionado pelo rolo de papel, quando comparado com os demais substratos.

As médias obtidas em relação ao comprimento do epicótilo das plântulas de pitangueira se encontram na Figura 3. Não houve interação significativa entre procedimentos de secagem e substratos. Dentre os procedimentos de secagem de sementes utilizados, a secagem à sombra permitiu a obtenção de plântulas com maior desenvolvimento do epicótilo $(5,25 \mathrm{~cm})$, duas vezes maior que o procedimento de secagem ao sol $(4,65 \mathrm{~cm})$.

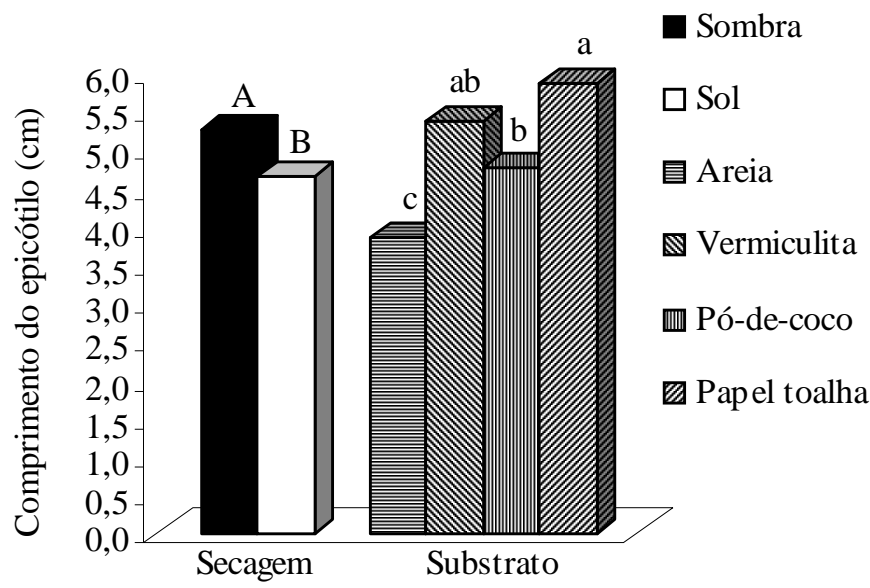

Médias seguidas da mesma letra maiúscula para os procedimentos de secagem e minúscula para os substratos, não diferem entre si pelo teste de Tukey a $5 \%$ de probabilidade. $\mathrm{CV}=13,19 \%$

Figura 3. Comprimento do epicótilo (cm por plântula) das plântulas de pitangueira (Eugenia uniflora L.) submetidas a diferentes procedimentos de secagem e substratos.

Referente aos substratos (Figura 3), o papel toalha e a vermiculita proporcionaram os melhores resultados de comprimento do epicótilo $(5,85$ e $5,37 \mathrm{~cm}$, respectivamente), apresentando o mesmo comportamento em relação ao comprimento da raiz (Figura 2). Constatou-se, novamente, que o substrato areia $(3,84 \mathrm{~cm})$ não proporcionou condições adequadas para o desenvolvimento das plântulas de pitangueira havendo redução de $34 \%$ do comprimento do epicótilo quando relacionado com o substrato papel toalha e de $28 \%$ referente ao substrato vermiculita.

Verificou-se interação significativa entre os procedimentos de secagem e os substratos quanto à massa seca de plântulas (Figura 4), enquanto as sementes secadas à sombra originaram plântulas de pitangueira com maior peso de massa seca, quando semeadas nos substratos vermiculita $(101,09 \mathrm{mg})$ e pó-de-coco $(94,62 \mathrm{mg})$, embora este último não tenha diferido do substrato papel toalha $(72,15 \mathrm{mg})$.
具Areia Vermiculita 血Pó-de-coco

四 Papel toalha

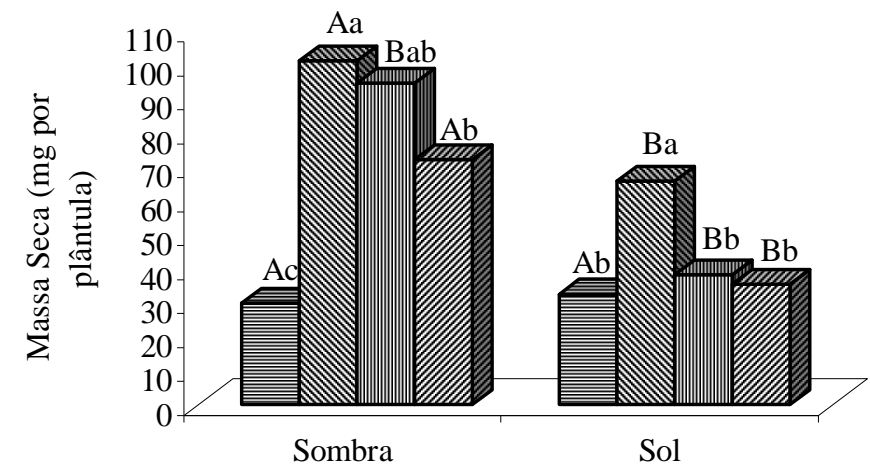

Médias seguidas da mesma letra maiúscula para os procedimentos de secagem e minúscula para os substratos, não diferem entre si pelo teste de Tukey a $5 \%$ de probabilidade. $\mathrm{CV}=21,46 \%$

Figura 4. M assa seca (mg por plântula) das plântulas de pitangueira (Eugenia uniflora L.) submetidas a diferentes procedimentos de secagem e substratos.

No procedimento de secagem à sombra (Figura 4), o substrato areia $(29,78 \mathrm{mg})$ ocasionou uma redução de $71 \%$ na massa seca das plântulas de pitangueira, comparado com as plântulas originadas em substrato vermiculita; já no procedimento de secagem ao sol o decréscimo foi de $35 \%$ em relação à vermiculita $(65,69 \mathrm{mg})$.

Da maturidade fisiológica até o momento de sua utilização na semeadura, as sementes estão sujeitas à perda da qualidade fisiológica pelas mudanças bioquímicas e fisiológicas que passam a ocorrer. A deterioração, em muitos casos imperceptível na fase inicial, se manifesta no decorrer do tempo, através de reflexos negativos no vigor (Garcia et al., 2004).

As sementes recalcitrantes não podem ser secadas abaixo de determinado teor de água sem que ocorram danos fisiológicos (Neves, 1994); assim, as sementes secadas ao sol (teor de água de $45 \%$ ) apresentaram menor vigor, sendo o procedimento de secagem à sombra (teor de água de $47 \%$ ) indicado para as sementes de pitangueira, já que se obteve menor tempo médio de germinação (Figura 2) e adequado desenvolvimento das plântulas, demonstrando o efeito recalcitrante desta semente que, ao reduzir em $2 \%$ o seu teor de água, ocasionou o início de sua deterioração.

A secagem a sombra também foi utilizada em sementes de Bactris gasipaes Kunth (Ferreira \& Santos, 1992); Machaerium stipitatum (DC.) Vog.) (Medeiros \& Zanon, 2000); e Carica papaya L. (Berbert et al., 2008).

Pesquisas relacionadas ao procedimento de secagem natural com espécies frutíferas, ainda não vêm sendo muito desenvolvidas, seja pela dificuldade no manuseio dessas espécies ou por se optar pelo método de secagem artificial. Dentre os trabalhos nos quais se empregou o método de secagem natural pode-se citar os realizados com sementes de maracujá-amarelo (Passiflora edulis Sims f. flavicarpa Deg.) (Martins et al., 2005; Carlesso et al., 2008); acerola (Malpighia puniciflora DC) (Azerêdo et al., 2006); e jaca (Artocarpus integrifolia L.) (Silva et al., 2007).

A escolha do substrato tem importância fundamental nos resultados do teste padrão de germinação; portanto, é imprescindível a utilização de um material inerte que não influencie no desenvolvimento das plântulas e facilite a sua avaliação 
permitindo, com isto, sustentabilidade da raiz e baixa contaminação por patógenos.

O substrato que melhor favoreceu o vigor das sementes de pitangueira foi a vermiculita. Apesar do substrato papel toalha promover maior comprimento radicular e do epicótilo, necessário para o estabelecimento da cultura em campo, neste substrato se constatou que as sementes levaram mais tempo para germinar e as plântulas obtiveram menor acúmulo de massa seca em relação ao substrato vermiculita. A redução de massa seca foi devida ao fato das raízes e da parte aérea se apresentarem muito delgadas e com poucas raízes secundárias, fato possível de ser comprovado através da Figura 4, ao ocorrer uma redução de 55\% na massa seca das plântulas de pitangueira derivadas das sementes submetidas a secagem à sombra, em relação àquelas secadas ao sol.

Referidos resultados foram obtidos porque o substrato vermiculita apresenta boa capacidade de absorção e retenção de água (Figliolia et al., 1993) e não exige reumedecimento diário (Pacheco et al., 2006), além de ter sido o substrato que menos favoreceu o surgimento de fungos, diferentemente do apresentado pelo substrato papel toalha.

A vermiculita tem proporcionado condições favoráveis para a germinação de sementes e vigor das plântulas de diferentes espécies, como o maracujá (Passiflora edulis Sims) (Pereira \& Andrade, 1994); itaubarana (Acosmium nitens (Vog.) Yakovlev) (Varela et al., 2005); jacarandá (Dalbergia nigra (Vell.) Fr. All. ex. Benth) (Andrade et al., 2006); aroeira do sertão (Myracrodruon urundeuva Fr. All.) (Pacheco et al., 2006); jabuticabeira (Myrciaria jaboticaba Berg.) cv. Sabará (Alexandre et al., 2006) e mulungu (Erythrina velutina Willd) (Alves et al., 2008).

A determinação do comprimento da raiz e da parte aérea das plântulas normais é válida haja vista que as sementes vigorosas originam plântulas com maior taxa de crescimento (Nakagawa, 1999). É conveniente que, juntamente, sejam também levadas em consideração a porcentagem e a velocidade de germinação para uma interpretação correta e segura dos resultados obtidos. Como todos esses parâmetros são obtidos a partir de plântulas normais, é necessário que as raízes estejam desenvolvidas o suficiente para que possam se estabilizar e desenvolver normalmente em campo.

O substrato areia, nas condições em que foi conduzido o experimento, não ocasionou resultados satisfatórios uma vez que se observou, em todos os parâmetros, redução no vigor das plântulas, em ambos os procedimentos de secagem, sendo este bastante inferior ao do substrato vermiculita, não devendo ser utilizado, portanto, para testes de germinação de sementes de pitangueira.

Segundo Figliolia et al. (1993), o substrato areia apresenta, como desvantagem, a desuniformidade na capacidade de retenção e distribuição da água já que esta tende a se depositar na parte inferior do substrato, o que compromete o desenvolvimento da plântula.

Tendo em vista a importância da secagem das sementes, deve-se buscar procedimentos de secagem que gerem baixa degradação ambiental, melhor relação custo-benefício e não ocasionem perdas de viabilidade e vigor das sementes para que, ao serem associados ao substrato ideal, proporcionem aumento de produção, obtenção de plântulas vigorosas e mais rentabilidade, sobretudo para os pequenos agricultores.

\section{CONCLUSÕES}

Nas condições em que o experimento foi realizado, recomenda-se, para testes de vigor, o procedimento de secagem à sombra e a semeadura entre substrato vermiculita.

\section{LITERATURA CITADA}

Alexandre, R. S.; Wagner Júnior, A.; Negreiros, J. R. S.; Bruckner, C. H. Estádio de maturação dos frutos e substratos na germinação de sementes e desenvolvimento inicial de plântulas de jabuticabeira. Revista Brasileira Agrociência, v.12, n.2, p.227-230, 2006.

Alves, E. U.; Andrade, L. A.; Barros, H. H. A.; Gonçalves, E. P.; Alves, A. U.; Gonçalves G. S.; Oliveira, L. S. B.; Cardoso, E. A. Substratos para testes de emergência de plântulas e vigor de sementes de Erythrina velutina Willd., Fabaceae. Semina: Ciências Agrárias, v.29, n.1, p.69-82, 2008.

Andrade, A. C. S.; Pereira, G. M. Efeito do substrato e da temperatura na germinação e no vigor de sementes de cedro - Cedrela odorata L. (Meliaceae). Revista Brasileira de Sementes, v.16, n.1, p.34-40, 1994.

Andrade, A. C. S.; Pereira, T. S.; Fernandes, M. J.; Cruz, A. P. M.; Carvalho, A. S. R. Substrato, temperatura de germinação e desenvolvimento pós-seminal de sementes de Dalbergia nigra. Pesquisa Agropecuária Brasileira, v.41, n.3, p.517-523, 2006.

Andrade, A. C. S.; Souza, A. F.; Ramos, F. N.; Pereira, T. S.; Cruz, A. P. M. Germinação de sementes de jenipapo: temperatura, substrato e morfologia do desenvolvimento pós-seminal. Pesquisa Agropecuária Brasileira, v.35, n.3, p.609-615, 2000.

Azerêdo, G. A.; Matos, V. P.; Lima, A. A.; Guedes, A. S.; Medeiros, A. Viabilidade de sementes de acerola (Malpighia punicifolia DC) influenciada pelo substrato, temperatura e coloração de frutos. Pesquisa Agropecuária Tropical, v.36, n.1, p.7-11, 2006.

Becwar, M. R.; Stanwood, P. C.; Leonhartdt, K.W. Dehydration effects on freezing characteristics and survival in liquid nitrogen of desiccation-tolerant and desiccation-sensitive seeds. Journal American Horticulture Science, v.108, n.4, p.613-618, 1983.

Berbert, P. A.; Carlesso, V. O.; Silva, R. F.; Araújo, E. F., Thiébaut, J. T. L.; Oliveira, M. T. R. Qualidade fisiológica de semente de mamão em função da secagem e do armazenamento. Revista Brasileira de Sementes, v.30, n.1, p.40-48, 2008.

Brasil. Ministério da Agricultura e Reforma Agrária. Regras para análise de sementes. Brasília: Departamento Nacional de Produção Vegetal, 1992. 365p.

Carlesso, V. O.; Berber, P. A.; Silva, R. F.; Detmann, E. Secagem e armazenamento de sementes de maracujá amarelo (Passiflora edulis Sims f. flavicarpa Degener). Revista Brasileira de Sementes, v.30, n.2, p.065-074, 2008.

Delgado, L.F. Tolerância à dessecação em sementes de espécies brasileiras de Eugenia. São Paulo: Instituto de Botânica da Secretaria do Meio Ambiente, 2006. 106p. Dissertação Mestrado

ESTAT - Sistema de Análise Estatística (ESTAT 2.0). Jaboticabal: Pólo Computacional do Departamento de Ciências Exatas da UNESP, 1994. 
Ferreira, A. G.; Borghetti, F. Germinação: Do básico ao aplicado. Porto Alegre: Artmed, 2004. 316p.

Ferreira, S. A. N.; Santos, L. A. Viabilidade de sementes de pupunha (Bactris gasipaes Kunth.). Acta Amazonica, v.22, n.3, p.303-307, 1992.

Figliola, M. B.; Oliveira, E. C.; Piña-Rodrigues, F.C.M. Análise de sementes. In: Aguiar, I. B.; Piña-Rodrigues, F. C. M.; Figliola, M. B.; (coord.). Sementes florestais tropicais. Brasília: ABRATES, 1993. cap.4, p.137-174.

Garcia, D. C.; Barros, A. C. S. A.; Peske, S.T.; Menezes, N. L. A secagem de sementes. Ciência Rural, v.34, n.2, p.603-608, 2004.

Gouveia, J. P. G. de; Almeida, F. de A. C.; Farias, E. S.; Silva, M. M. da; Chaves, M. da C. V.; Reis, L. S. Determinação das curvas de secagem em frutos de cajá. Revista Brasileira de Produtos Agroindustriais, v.1, n.especial, p.63-68, 2003.

Kohama, S.; Maluf, A. M.; Bilia, D. A. C.; Barbedo, C. J. Secagem e armazenamento de sementes de Eugenia brasiliensis LAM. (grumixameira). Revista Brasileira de Sementes, v.28, n.1, p.72-78, 2006.

Marcos Filho, J. Fisiologia de sementes de plantas cultivadas. Piracicaba: FEALQ, 2005. 495p.

Marcos Filho, J.; Cícero, S. M.; Silva, W. R. Avaliação da qualidade das sementes. Piracicaba: FEALQ, 1987. 230p.

Martins, L.; Silva, W.R.; Meletti, L. M. M. Conservação de sementes de maracujá-amarelo (Passiflora edulis SIMS F. flavicarpa DEG.). Revista Brasileira de Sementes, v.27, n.1, p.183-189, 2005.

Medeiros, A. C. S.; Zanon, A. Efeitos do substrato e da temperatura na germinação de sementes de branquilho (Sebastiania commersoniana (Baillon) L. B. Smith; R.J. Down) e de pinheiro-bravo (Podocarpus lambertii Klotzch ex Ndl.). Boletim de Pesquisa Florestal, n.36, p.21-28, 1998.

Medeiros, A. C. S.; Zanon, A. Armazenamento de sementes de sapuva (Machaerium stipitatum). Boletim de Pesquisa Florestal, n.40, p.57-66, 2000.

Nakagawa, J. Testes de vigor baseados no desempenho das plântulas. In: Krzyzanowski, F. C.; Vieira, R. D.; França Neto, J. B. Vigor de sementes: Conceitos e testes. Londrina: ABRATES, 1999. p.2.1-2.24.

Neves, C. S. V. J. Sementes recalcitrantes. Pesquisa Agropecuária Brasileira, v.29, n.9, p.1459-1467, 1994.
Oliveira, E. E. Morfologia e análise de plântulas florestais. In: Aguiar, I.B.; Piña-Rodrigues, F. C. M.; Figliolia, M. B. Sementes florestais tropicais. Brasília: ABRATES, 1993. cap.5, p.175-214.

Pacheco, M. V; Matos, V. P.; Feliciano, A. L. P.; Ferreira, R. L. C. Germinação de sementes e crescimento inicial de plântulas de Tabebuia aurea (Silva Manso) Benth. \& Hook f. ex S. Moore. Revista Ciência Florestal, v.18, n.2, p.143-150, 2008.

Pacheco, M. V.; Matos, V. P.; Ferreira, R. L. C.; Feliciano, A. L. P.; Pinto, K. M. S. Efeito de temperaturas e substratos na germinação de sementes de Myracrodruon urundeuva Fr. All. (Anacardiaceae). Revista Árvore, v.30, n.3, p.359-367, 2006.

Pacheco, M. V.; Matos, V. P.; Ferreira, R. L. C.; Feliciano, A. L. P.; Pinto, K. M. S. Germinação de sementes de Apeiba tibourbou Aubl. em função de diferentes substratos e temperaturas. Scientia Florestalis, n.73, p.19-25, 2007.

Paiva, H. N.; Gonçalves, W. Insumos. In: Produção de mudas. Viçosa: Aprenda Fácil, 2001. cap.3, p.21-31. (Coleção Jardinagem e Paisagismo. Série Arborização Urbana, v.1).

Pereira, T. S.; Andrade, A. C. S. Germinação de Psidium guajava L. e Passiflora edulis SIMS - efeito da temperatura, substrato e morfologia do desenvolvimento pós-seminal. Revista Brasileira de Sementes, v.16, n.1, p.58-62, 1994.

Roberts, E. H. Predicting the storage life of seed. Seed Science and Technology, v.1, n.3, p.499-514, 1973.

Sete Ervas. Pitangueira. 2004. http://www.seteervas.com.br/download/SeteErvas_Pitangueira.pdf. 20 Fev. 2008.

Silva, J. B. C.; Nakagawa, J. Estudo de fórmulas para cálculo da velocidade de germinação. Informativo ABRATES, v.5, n.1, p.62-73, 1995.

Silva, S. M. Pitanga. Revista Brasileira de Fruticultura, v.28, n.1, p.1-159, 2006.

Silva, T. T. A.; Souza, L. A.; Oliveira, L. M.; Guimarães, R. M. Temperatura de germinação, sensibilidade à dessecação e armazenamento de sementes de jaqueira. Revista Ciência Agronômica, v.38, n.4, p.436-439, 2007.

Varela, V. P.; Costa, S. S.; Ramos, M. B. Influência da temperatura e do substrato na germinação de sementes de itaubarana (Acosmium nitens (Vog.) Yakovlev)-Leguminosae, Caesalpinoideae. Acta Amazônica, v.35, n.1, p.35-39, 2005.

Vieira, R. D.; Carvalho, N. M. Testes de vigor em sementes. Jaboticabal: FUNEP, 1994. 164p. 